\title{
Estimando os impactos do aumento do ICMS na economia gaúcha: uma análise de insumo-produto
}

Henrique Morrone

\begin{abstract}
Resumo: A crise financeira do Rio Grande do Sul impõe grandes desafios ao governo a fim de mitigar tal situação. Corte de gastos e aumento de impostos em geral estão na agenda do governo sem mensurar adequadamente o impacto dessas medidas na economia. O objetivo do artigo é justamente preencher essa lacuna, verificando a estrutura básica da economia gaúcha em 2008, bem como estimando o impacto do aumento dos impostos sobre circulação de mercadorias e serviços (ICMS) na demanda final e na atividade econômica gaúcha. Para tal, este artigo emprega a Matriz de Insumo-Produto de 2008 com o objetivo de verificar o impacto do aumento dos impostos na economia. Os resultados mostram um impacto negativo do aumento dos impostos na economia gaúcha, restringindo as possibilidades de desenvolvimento regional.
\end{abstract}

Palavras-chave: Análise de insumo-produto qualitativa; Desenvolvimento Econômico.

Classificação JEL: O1, C1, D57.

Estimating the impacts of ICMS increases in the Gaúcha economy: An Input-output Analysis

\begin{abstract}
The financial crisis of Rio Grande do Sul imposes great challenges to the state in order to mitigate the situation. Cutting spending and general tax increases are on the government agenda without access the impact of these measures on the economy. The aim of this paper is precisely to fill this gap by checking the basic structure of the state economy in 2008, as well as estimating the impact of the tax increases in final demand and the state's economic activity. To that end, this paper uses the Input-Output Matrix for 2008 to investigate the impact of higher taxes on the economy. The results show a negative impact of higher taxes on the state's economy, restricting the regional development possibilities.
\end{abstract}

Key-words: Qualitative input-output analysis; Development Economics.

JEL Classification: O1, C1, D57.

6 Doutor em Economia pela University of Utah. Professor Adjunto do Departamento de Economia e Relações Internacionais da Universidade Federal do Rio Grande do Sul. E-mail: hmorrone@hotmail.com 


\section{Introdução}

Uma das questões centrais em economia diz respeito à mensuração do impacto do aumento de impostos nas economias subnacionais. Os aumentos de impostos têm sido considerados pelos governos como estratégias saneadoras de suas situações fiscais. Acreditam que o aumento de impostos no curto prazo acarretará aumento da arrecadação, gerando um alívio fiscal a fim de que outras medidas futuras sejam tomadas. Ademais, apostam na inelasticidade de produtores e consumidores para atingir uma situação fiscal mais adequada. Assim, desconsideram os efeitos negativos do aumento de impostos e queda dos gastos públicos nas atividades produtivas.

Existe uma vasta literatura sobre os impactos dos impostos na economia. Impostos têm o potencial de provocar distorções nos preços relativos, afetando de forma desigual consumidores, produtores e o próprio governo. Dependendo da composição da estrutura dos impostos (entre impostos diretos e indiretos), os custos em termos de ganhos ou perdas de bem-estar podem ser aumentados ou reduzidos. De um modo geral, economistas tendem a preferir impostos diretos em detrimento de impostos indiretos, pois os primeiros seriam neutros, ou seja, não afetariam os preços relativos evitando problemas de distorções artificiais na economia. Esses impostos diretos seriam interpretados como se funcionassem como um imposto indireto com igual alíquota para todos os bens da economia.

Nesse sentido, um estudo importante nessa área é Harberger (1964). Nele, o autor mostra que a preferência por impostos diretos não é tão evidente. Exemplificando para o caso de uma economia com apenas três bens (vinho, pão e lazer), o autor demonstra que tanto impostos indiretos quanto impostos diretos afetariam os preços relativos, causando distorções na economia. Impostos indiretos causariam alterações nos preços relativos dos bens (vinho e pão), permanecendo inalterada a relação entre os bens e o lazer. No caso dos impostos diretos, entretanto, as distorções se concentrariam entre os bens individuais e o lazer. Harberger (1964) mostra que não existe diferença qualitativa entre os impostos no que tange aos seus efeitos na economia. Nesse caso, análises quantitativas devem ser empregadas caso a caso, a fim de verificar qual o imposto mais efetivo para determinada economia. Harberguer conclui afirmando que impostos diretos seriam superiores aos impostos indiretos quando esses últimos não são generalizados na economia (abarcam uma quantidade pequena e concentrada de bens) e incidem apenas em bens com baixa elasticidade-preço da demanda. Do contrário, não existe uma superioridade significativa dos impostos diretos sobre os indiretos.

Cabe frisar, contudo, que o estado do Rio Grande do Sul possui autonomia fiscal limitada, sendo o imposto indireto ICMS (imposto sobre circulação de mercadorias e serviços) sua principal fonte de receita. Nesse contexto, o aumento de impostos impacta os produtores, os consumidores e o governo, afetando também o bem-estar econômico da região. Nessa linha, alguns trabalhos tentaram avaliar o impacto de reformas tributárias para o Rio Grande do Sul (RS). Fochezatto (2002) 
estimou o resultado de mudanças tributárias na economia gaúcha. Porsse (2005) examinou o efeito de uma política de incentivo fiscal para o Estado. Além disso, estudos mais recentes como Marques Júnior e Oliveira (2015) estimaram as elasticidades de curto e longo prazos do ICMS no Rio Grande do Sul. Logo, prever o efeito do aumento dos impostos nas atividades econômicas do RS torna-se importante para o melhor entendimento do funcionamento da economia regional.

O presente artigo tem por objetivo principal mensurar o impacto do aumento no Imposto sobre Circulação de Mercadorias e Serviços (ICMS) nos setores da economia gaúcha, exceto as atividades com múltiplas ligações fortes, empregando a matriz de insumo-produto do Rio Grande do Sul para o ano de 2008. Primeiramente, verificar-se-á quais setores do grupo que apresentam relações intersetoriais fortes possuem o menor número de ligações. A partir daí, pretende-se averiguar o impacto do aumento em 5\% do ICMS nesses setores em dois cenários. No primeiro, todo o aumento do imposto (arrecadação extra) é deduzida da demanda final. No segundo cenário, além da redução da demanda proveniente do Cenário 1, é adicionado um efeito preço que reduz ainda mais a demanda final. Os resultados mostram um impacto negativo dos impostos na atividade econômica gaúcha no curto e médio prazos. Com relação à fonte dos dados empregados no artigo, utilizaram-se os dados da Matriz de Insumo-Produto de 2008 da Fundação de Economia e Estatística do RS (FEE-RS).

O artigo está organizado em quatro seções além dessa introdução: a seção 2 apresenta a metodologia e a fonte de dados brutos; a seção 3 exibe os resultados da estrutura produtiva da economia gaúcha; a seção 4 exibe os resultados; e a parte final apresenta as conclusões.

\section{Metodologia e Fonte de Dados Brutos}

Na presente seção, apresentar-se-á a metodologia e a fonte de dados empregada no artigo. Ambas serão cruciais para fundamentar a análise dos resultados presentes nas próximas seções.

\subsection{Método}

A estrutura das economias pôde ser melhor analisada graças aos trabalhos pioneiros de Leontief para a economia americana (Leontief, 1986).O modelo de insumo-produto formulado por Leontief tem raízes pré-clássicas, que remontam ao trabalho dos fisiocratas, principalmente Quesnay. É notória também a influência dos esquemas de reprodução de Marx no trabalho desenvolvido por Leontief. O sistema simplificado de Leontief pode ser observado na Equação 1, disposta a seguir.

$$
x=(I-B)^{-1} f_{n}
$$




\section{Sendo:}

$x=\mathrm{o}$ vetor dos valores brutos de produção setoriais;

$B=$ a matriz de coeficientes técnicos de produção;

$f_{n}=$ vetor de demanda final setorial.

A matriz B é definida como a matriz de coeficientes técnicos diretos; ela mede apenas impactos diretos nas atividades. A matriz (I-B) $)^{-1} e ́$ conhecida como a matriz de Leontief, que representa os coeficientes técnicos diretos e indiretos. O modelo de insumo-produto de Leontief, apresentado na Equação 1, informa a produção (x) necessária para atender a um determinado incremento na demanda final $\left(f_{n}\right)$.

Parte fundamental desse modelo é a matriz inversa de Leontief. Esse modelo torna-se adequado para análises de curto e médio prazos, pois há evidência empírica de que a matriz inversa não sofre alterações substanciais ao longo do tempo.

Obtendo-se os resultados quanto ao aumento da produção necessária para atender a um acréscimo da demanda final, pode-se calcular seu impacto no aumento do emprego e do valor adicionado. Visto que, para produzir uma quantidade maior, as atividades necessitam de mais trabalhadores, os cálculos dos resultados em termos da estimação do aumento do emprego tornam-se triviais. Assume-se que, para isso, existe uma proporção fixa entre o pessoal ocupado $(\mathrm{PO})$ e a produção $(\mathrm{x})$. $\mathrm{O}$ multiplicador do emprego (ou pessoal ocupado) pode ser representado matematicamente abaixo.

$$
L=P O / x
$$

Onde:

$\mathrm{LxB}=$ multiplicador de impacto direto do emprego;

$L(I-B)^{-1}=$ multiplicador de impacto direto e indireto do emprego. O mesmo mede o impacto em termos de emprego de todos os setores que fornecem produtos intermediários, direta e indiretamente, a uma determinada atividade.

Desenvolvimentos posteriores do modelo de insumo-produto focaram nos aspectos qualitativos da estrutura produtiva básica das economias. Tentavam detectar os setores importantes (ou mais dinâmicos) a fim de obter um melhor entendimento do funcionamento das economias. Em um estudo pioneiro, Schintke e Staglin (1988) calcularam os setores mais importantes para a economia por meio de alterações nas colunas da matriz de coeficientes técnicos de produção. Os coeficientes importantes (CIs), ou dinâmicos, causariam as maiores mudanças potenciais no valor bruto da produção. Em outras palavras, o método visava estimar o efeito nos elementos da matriz inversa de Leontief, fruto de uma pequena mudança nos elementos da matriz de coeficientes técnicos, matriz B (Aroche-Reyes, 1996). O processo de identificação desses coeficientes importantes será exposto a seguir.

O procedimento de cálculo dos coeficientes importantes (CIs) envolve quatro passos. Primeiro, deve-se construir a matriz de coeficientes técnicos (B) e a 
matriz de Leontief para o ano escolhido, caso ela não esteja disponível pelo governo. $\mathrm{Na}$ sequência, seguimos a literatura padrão para encontrarmos os coeficientes importantes, CIs (Aroche-Reyes, 2002). Para acharmos os CIs, transformamos as duas matrizes utilizando a Equação 3 para estimar os coeficientes ${ }^{r}$ para cada um dos setores $(\mathrm{i}, \mathrm{j})$.

$$
r_{i j}=\frac{1}{a_{i j}\left[\alpha_{j i}+100 *\left(\alpha_{i i} / \delta_{i}\right) \delta_{j}\right]}
$$

Onde:

$a_{i j}=$ um elemento da matriz de coeficientes técnicos diretos (B);

$\alpha_{j i}=$ um elemento da matriz inversa de Leontief;

$\delta_{i}=$ valor bruto da produção do setor i;

$\delta_{j}=$ valor bruto da produção do setor $\mathrm{j}$.

Terceiro, aplicamos um filtro de seleção exógeno a fim de transformarmos novamente a matriz de coeficientes $r_{i j}$ em matrizes binárias, contendo apenas os números zero(0) e um(1). O procedimento padrão é considerar esse filtro como sendo igual a 0,20, ou 20\% (Aroche-Reyes, 2002). Valores inferiores ao informado anteriormente são considerados coeficientes importantes (CIs), assumindo valores iguais a 1. Relações intersetoriais fortes são definidas pelo número 1(um), enquanto ligações fracas ou inexistentes por 0 (zero). A partir dessa etapa, construímos matrizes binárias, também conhecidas como matrizes adjacentes.

Por fim, procedemos à construção das redes de ligação intersetoriais. Por exemplo, a matriz $\mathrm{Z}$ abaixo pode ser representada por uma rede de relações (grafo ou dígrafo). Cada elemento igual a um(1) indica uma ligação forte CI.

$\mathbf{Z}=$\begin{tabular}{|c|c|c|c|}
\hline Setores & Agricultura & Indústria & Serviços \\
\hline Agricultura & 0 & 1 & 0 \\
Indústria & 1 & 0 & 1 \\
Serviços & 0 & 1 & 0 \\
\hline
\end{tabular}

A matriz $\mathrm{Z}$ pode ser representada pela network a seguir. Uma seta saindo de um vértice (setor) indica que esse setor compra um produto de outro setor. Pode-se exibir essa matriz, mostrando a relação entre os setores por meio de um dígrafo D. Nele, por exemplo, podemos visualizar que o setor de serviços (3) compra da atividade industrial (2), representando uma ligação forte entre eles. 


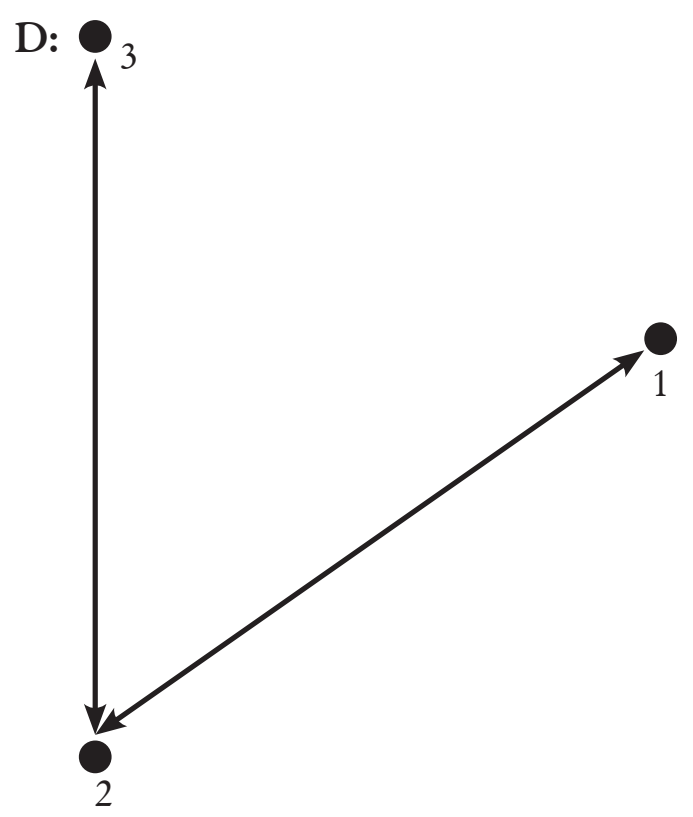

Depois de representar-se a estrutura da economia por meio dos dígrafos, pode-se averiguar quais setores possuem um menor número de interligações fortes. Esses setores, juntamente com os setores com ligações fracas, sofrerão o impacto do aumento do ICMS conforme descrito abaixo.

Existem formas variadas para selecionar os setores-chave da economia. Alguns exemplos de técnicas alternativas são os métodos tradicionais de Rasmussen (1956), Dietzembacher (1992) e Hewings et al. (1989). Contudo, a opção foi escolhida, pois atende aos principais propósitos de nosso estudo, detectando os setores-chave da economia e evitando as incertezas e imperfeições decorrentes do processo de construção das matrizes de insumo-produto.

A última etapa da simulação consiste na estimação do impacto do aumento de impostos na demanda e na atividade produtiva local. Para isso, será considerado o aumento de 5\% no ICMS de todos os setores, exceto os CIs com múltiplas ligações fortes. Seguindo Borges e Montibeler (2014), dois cenários serão empregados. O primeiro envolve o aumento do ICMS em $5 \%$, sendo que esse montante de arrecadação é totalmente transferido à demanda final dos setores. Considera-se que gastos do governo e exportações são constantes.

$$
f n_{1}=f n_{0}-i * u
$$

Sendo:

$f n_{1}$ : demanda final com o aumento do ICMS;

$f n_{0}$ : demanda final inicial; 
i: vetor da arrecadação do imposto ICMS por atividade;

u: vetor relativo ao aumento do ICMS para os setores da economia gaúcha, exceto para os CIs com múltiplas ligações.

No segundo cenário, além do decréscimo da demanda provocado no Cenário 1, incorporou-se também um efeito preço proveniente do aumento do ICMS. Aqui também se considera que gastos do governo e exportações são constantes. A equação simplificadora desse cenário está exposta a seguir. Nota-se que o potencial de repasse dos preços por parte das empresas ao consumidor final é bastante reduzido dada a frágil situação da economia.

$$
f n_{2}=0,98 f n_{0}-i^{*} u
$$

Os choques de demanda dos dois cenários incidirão sobre a matriz inversa de Leontief, impactando na produção, valor adicionado bruto e emprego. A análise das estimações presume que os impactos efetivos do aumento do ICMS estariam situados entre os dois cenários no curto e médio prazos. Assim, o procedimento desenvolvido é um método adequado para examinarmos o choque do aumento dos impostos no valor bruto da produção, no valor adicionado, no emprego gaúcho e na arrecadação de impostos. Isso permitirá acessar o impacto do aumento de impostos na economia gaúcha. Outros métodos que poderiam ser utilizados para acessar o efeito dos impostos na economia seriam os modelos de equilíbrio geral computável e estudos microeconométricos para a estimação de elasticidades dos impostos. (Para maiores detalhes, ver Fochezatto (2002) e Pintos-Payeras (2009)).

Contudo, a metodologia empregada no presente estudo apresenta duas limitações. A primeira consiste na análise dos dígrafos que abstrai a questão espacial, desconsiderando a localização das relações intersetoriais (Souza, 1989). Outra limitação do método está relacionada à perda de informações, dada a eliminação das relações fracas entre os setores produtivos. Apesar disso, acreditamos que essas limitações não prejudicam a qualidade dos resultados encontrados no presente estudo.

\subsection{Fonte de Dados}

Neste artigo, empregamos os dados da matriz de insumo-produto da Fundação de Economia e Estatística do Rio Grande do Sul (FEE/RS) para o ano de 2008. A partir daí, procedemos ao processo de transformação das matrizes quantitativas para matrizes binárias ou adjacentes. Ou seja, construímos matrizes cuja relação entre dois setores é expressa pelo número 1 (um) e a ausência de relação é simplesmente 0 (zero). Para chegarmos a essas matrizes binárias, empregamos um filtro (ver Equação 3) seguindo Aroche-Reyes (1996) e Gosh e Roy (1998). Os 37 setores selecionados foram: agricultura (1), pecuária e pesca (2), indústria extrativa (3), 
alimentos e bebidas (4), produtos do fumo (5), têxteis (6), produtos de madeira (7), celulose e produtos de papel (8), jornais e revistas (9), refino de petróleo e gás (10), álcool (11), artigos de borracha e plástico (12), produtos de minerais não metálicos (13), fabricação de aços e derivados (14), metalurgia de metais não ferrosos (15), produtos de metal (16), máquinas e equipamentos (17), eletrodomésticos (18), máquinas para escritório e informática (19), máquinas e materiais elétricos (20), material eletrônico e equipamentos de comunicações (21), aparelhos/instrumentos médico-hospitalar, medida e óptico (22), indústria automobilística (23), outros equipamentos de transporte (24), móveis e produtos das indústrias diversas (25), produção e distribuição de eletricidade e gás, água, esgoto e limpeza urbana (26), construção civil (27), comércio e serviços de manutenção e reparação (28), serviços de alojamento e alimentação (29), transporte, armazenagem e correio (30), serviços de informação (31), intermediação financeira e seguros (32), serviços prestados às empresas (33), atividades imobiliárias e aluguéis (34), administração, saúde e educação públicas e seguridade social (35), serviços prestados às famílias e associativa (36), e outros serviços (37). A composição e classificação desses setores seguem a Classificação Nacional de Atividades Econômicas(CNAE) do IBGE.

\section{Uma Análise da Estrutura Econômica Gaúcha em 2008}

Nesta seção examinaremos os principais resultados encontrados. Primeiro, procederemos à análise dos coeficientes importantes (CIs) para o ano de 2008. Em seguida, analisaremos, em maiores detalhes, os dígrafos da economia estadual.

Nossas estimações indicam que a economia gaúcha possui 56 CIs em 2008. Isso indica que a economia local apresenta 56 coeficientes importantes da matriz de coeficientes técnicos diretos de Leontief que, quando alterados, causariam as maiores mudanças potencias no valor bruto da produção (Aroche-Reyes, 1996). Essas seriam as ligações mais fortes da economia gaúcha, sinalizando os setores mais dinâmicos da região.

Outrossim, da totalidade das CIs, observamos que 20 delas estão localizadas na diagonal principal da matriz adjacente (Para detalhes, ver Apêndice). Analisando-se o número de coeficientes importantes na diagonal principal da matriz adjacente do ano de 2008 , verificamos que $54 \%$ da totalidade dos setores são usuários substanciais de seus próprios produtos. De um modo geral, espera-se encontrar um maior número de CIs na diagonal principal, tendo em vista que os coeficientes da matriz inversa de Leontief e da matriz de coeficientes técnicos diretos são maiores nessa região. Assim, observamos que o grau de ligações intrasetoriais é modesto.

$\mathrm{Na}$ Figura 1, pode-se verificar a rede (network, ou dígrafo) da economia gaúcha para o ano de 2008. Os 37 setores da economia estão representados pelos vértices encontrados na figura. Uma seta partindo de um setor "i" para um setor “j” indica que o último é um importante usuário (comprador) do produto do setor "i". 
Analisando-se a Figura 1, é possível observar as ligações fortes entre os setores. Nela estão dispostas as relações setoriais básicas da economia gaúcha para o ano de 2008. Na Figura 1, podemos complementar a análise, localizando as áreas da network que possuem maior concentração de coeficientes importantes. Examinando$-a$, constatamos fortes conexões entre os setores de metalurgia de metais não ferrosos (15), produtos de metal (16), máquinas e equipamentos (17), eletrodomésticos (18), máquinas e materiais elétricos (20), medida e óptico (22), e indústria automobilística (23). Esses setores apresentam maior integração, possuindo um número substancial de ligações fortes. Os CIs em questão apresentam coeficientes técnicos diretos de Leontief que, quando alterados, causam as maiores mudanças potencias no valor bruto da produção (Aroche-Reyes, 1996). Assim, políticas governamentais que visariam o estimulo à expansão produtiva via redução de impostos deveriam se concentrar nessas áreas. De forma análoga, políticas de aumentos de impostos devem concentrar-se longe dessas áreas a fim de minimizar seu impacto negativo sobre o nível de atividade da economia.

Assim, os resultados mostram a importância dos setores para a economia no período. De um modo geral, a economia gaúcha apresenta um número reduzido de CIs, estando ela concentrada na diagonal principal da matriz adjacente. Isto indica um grau modesto de relações intrasetorias e intersetoriais da economia regional. Além disso, a atividade de infraestrutura (principalmente construção civil e produção e distribuição de eletricidade e água) apresentou resultados pífios, podendo restringir o crescimento sustentável da economia gaúcha. Esses resultados fornecem uma melhor compreensão da estrutura da economia em questão, servindo de guia para os formuladores de políticas econômicas.

Figura 1: Representação das relações setoriais básicas do grafo da economia gaúcha para o ano 2008.

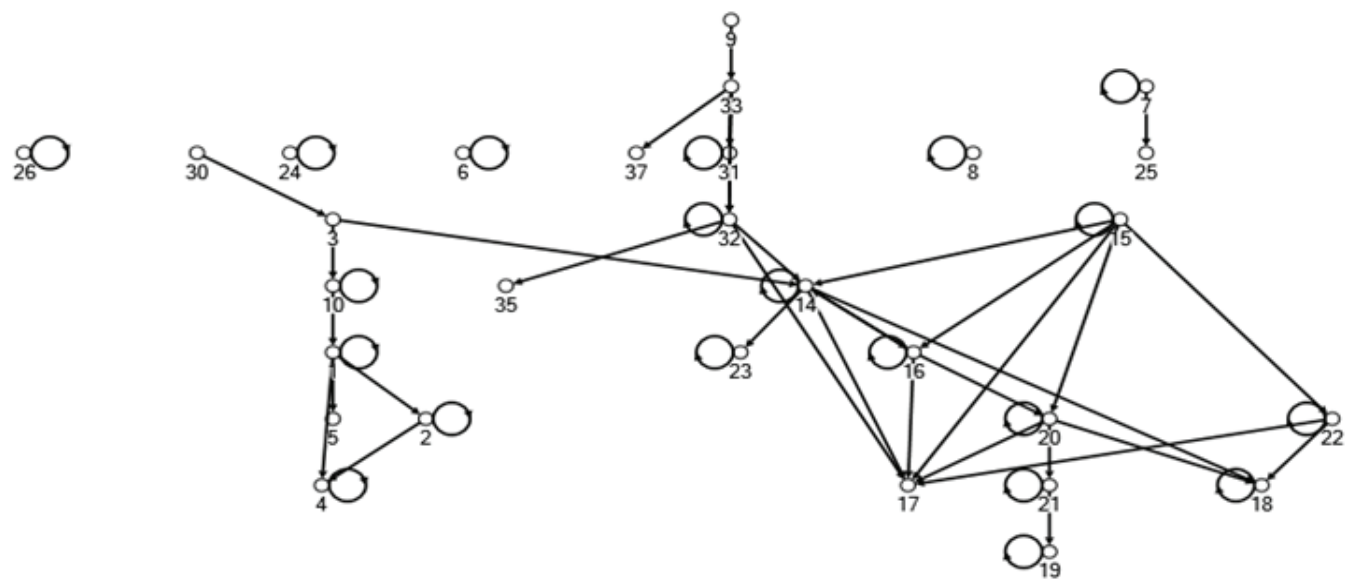

Fonte: elaboração própria.

Nota: Foi empregado o software NodeXL a fim de estimar a rede de conexões intersetoriais. 


\section{Resultados}

Nesta seção, são analisados os efeitos de dois cenários: um aumento do ICMS de $5 \%$ nos setores da economia, exceto os CIs mais interconectados da Figura 1, e o mesmo aumento do ICMS adicionado de um efeito preço que intensifica ainda mais a queda da demanda final. Especificamente, os setores atingidos pelo aumento do ICMS seriam: agricultura (1), pecuária e pesca (2), indústria extrativa (3), alimentos e bebidas (4), produtos do fumo (5), têxteis (6), produtos de madeira (7), celulose e produtos de papel (8), jornais e revistas (9), refino de petróleo e gás (10), álcool (11), artigos de borracha e plástico (12), produtos de minerais não metálicos (13), fabricação de aços e derivados (14), máquinas para escritório e informática (19), material eletrônico e equipamentos de comunicações (21), outros equipamentos de transporte (24), móveis e produtos das indústrias diversas (25), produção e distribuição de eletricidade e gás, água, esgoto e limpeza urbana (26), construção civil (27), comércio e serviços de manutenção e reparação (28), serviços de alojamento e alimentação (29), transporte, armazenagem e correio (30), serviços de informação (31), intermediação financeira e seguros (32), serviços prestados às empresas (33), atividades imobiliárias e aluguéis (34), administração, saúde e educação públicas e seguridade social (35), serviços prestados às famílias e associativa (36), e outros serviços (37). Acredita-se que os resultados ficariam situados no intervalo definido pelos resultados dos dois cenários.

\subsection{Impactos no Valor Bruto da Produção e no Valor Adicionado Bruto e na Arrecadação}

Os aumentos do ICMS de 5\% no Cenário 1, concentrados principalmente nos setores CIs com menos ligações intersetoriais e nos setores com ligações fracas, engendrou uma queda de $0,24 \%$ no valor bruto da produção da economia gaúcha. Ou seja, o valor bruto da produção gaúcha apresentou uma queda de aproximadamente 965 milhões de reais. Essa redução deve-se ao efeito da queda da demanda setorial que, via seus encadeamentos setoriais, causou a redução da produção gaúcha.

$\mathrm{Na}$ esfera mesoeconômica, os setores que sofreram o maior impacto negativo foram, em ordem: refino de petróleo e gás, alimentos e bebidas, produção e distribuição de água e eletricidade, serviços de informação e agricultura. Esses setores apresentaram as maiores quedas de produção, afetando negativamente os demais setores da economia via seus multiplicadores para frente e para trás no processo produtivo (Tabela 1 ).

No Cenário 2, encontrou-se uma queda no valor bruto da produção estadual de $1,75 \%$. Em outras palavras, observou-se uma queda de aproximadamente 6,9 bilhões de reais. Os setores que apresentaram maior redução da produção foram comércio e serviços de manutenção (R $\$ 761,6$ milhões), refino de petróleo e gás (R\$ 693 milhões), alimentos e bebidas (R\$ 536 milhões de reais), transporte (R\$ 330 milhões), e agricultura (R\$323 milhões). 
A Tabela 2 apresenta os resultados no que se refere ao aumento do valor adicionado bruto (VAB) nos dois cenários. No Cenário 1, verificou-se uma queda de 315,5 milhões de reais no valor adicionado bruto da economia gaúcha, uma redução de $0,18 \%$ no VAB da economia. No nível setorial, as atividades que apresentaram a maior redução do VAB foram a agricultura e os serviços de informação.

Já no Cenário 2, como esperado, a queda foi mais acentuada. Houve um decréscimo no VAB de $1,82 \%$. Essa queda foi ocasionada pela agricultura, comércio e serviços de manutenção, atividades imobiliárias, e transportes. Acreditamos que o resultado efetivo de um aumento do ICMS na demanda final e na atividade econômica gaúcha concentre-se entre esses dois cenários.

Por fim, cabe fazer alguns comentários sobre os possíveis impactos do aumento da alíquota do ICMS na arrecadação estadual. A Secretaria da Fazenda do Rio Grande do Sul espera arrecadar 31,04 bilhões de reais com o aumento das alíquotas do ICMS. A Tabela 3 apresenta a sequência anual de arrecadação do ICMS para a economia gaúcha, incluindo a projeção de aumento de arrecadação para o ano de 2016.

A projeção de aumento de arrecadação do ICMS está baseada numa estimativa de crescimento do produto nacional de aproximadamente $1,3 \%$, algo bastante improvável visto que a economia nacional se encontra numa profunda recessão. Nesse sentido, Cruz (2016), após analisar a Lei de Diretrizes Orçamentárias (LDO), argumenta que a projeção de aumento da arrecadação está vinculada a projeções irreais para o desempenho da economia nacional. Isso coloca em dúvida a efetividade do aumento do ICMS como motivo para aumentar a arrecadação do governo.

Comparando-se a arrecadação de 2015 com a projetada para 2016, o governo espera um aumento da receita de aproximadamente $4,33 \%$. Nesse sentido, um exercício interessante seria verificar se o aumento estimado de receita é compatível ou não com o impacto na produção descrito nos dois cenários de simulação do presente estudo.

Iniciando-se a análise pelo Cenário 1, observa-se que tanto o valor bruto da produção quanto o valor adicionado bruto apresentam uma queda de 0,24\% e 0,18\% respectivamente. Além do mais, verifica-se que essas quedas na atividade econômica não são compatíveis com as projeções de crescimento da LDO e, consequentemente, com o aumento de receita projetado pelo governo.

Quando as projeções do governo estadual são confrontadas com os resultados do Cenário 2, as diferenças tornam-se ainda maiores. Os resultados do Cenário 2 incluem, além do decréscimo da demanda, um efeito preço proveniente do aumento do ICMS. Segundo as estimativas, o valor bruto da produção cairá 1,75\% e o valor adicionado bruto sofrerá uma queda de 1,82\%. Assim como no Cenário 1, esses resultados também são incompatíveis com as projeções de crescimento do produto e da arrecadação constantes na LDO.

Desse modo, a arrecadação do governo do RS dificilmente apresentará o aumento estimado pela Secretaria da Fazenda do Rio Grande do Sul. O mais provável é que o crescimento do produto seja negativo, devido à recessão nacional. Acreditamos que os resultados, em termos de variações do produto, fiquem dentro dos dois 
cenários apresentados. O Cenário 2 é um pouco mais pessimista, pois incorpora um efeito preço decorrente do aumento do ICMS. Nesse sentido, caso a recessão nacional se aprofunde, o próprio efeito preço será limitado, tendo em vista uma menor capacidade por parte das empresas de repasse do aumento do imposto para os consumidores finais. Nossos resultados, portanto, vão de encontro às previsões por parte do governo do RS de aumento da arrecadação.

\section{Tabela 1: Queda do Valor Bruto da Produção Gaúcha decorrente do aumento de $5 \%$ do ICMS para setores selecionados.}

(Milhões R\$)

\begin{tabular}{|c|c|c|}
\hline \multirow{2}{*}{$\begin{array}{rr} & \text { Atividades } \\
\end{array}$} & \multicolumn{2}{|c|}{ Queda no valor bruto da produção } \\
\hline & Cenário 1 & Cenário 2 \\
\hline Agricultura, silvicultura e exploração florestal (1) & 82,8 & 323,0 \\
\hline Pecuária e pesca (2) & 51,3 & 202,7 \\
\hline Indústria extrativa (3) & 9,2 & 6,2 \\
\hline Alimentos e bebidas (4) & 105,2 & 536,0 \\
\hline Produtos do fumo (5) & 18,9 & 108,7 \\
\hline Têxteis, artefatos do vestuário e do couro, acessórios e calçados (6) & 42,5 & 244,2 \\
\hline Produtos de madeira — exclusive móveis (7) & 6,1 & 29,2 \\
\hline Celulose e produtos de papel (8) & 10,4 & 31,3 \\
\hline Jornais, revistas, discos (9) & 4,9 & 38,5 \\
\hline Refino de petróleo e gás e produtos químicos (10) & 251,6 & 693,6 \\
\hline 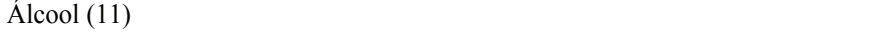 & 0,0 & 0,0 \\
\hline Artigos de borracha e plástico (12) & 6,0 & 96,2 \\
\hline Produtos de minerais não metálicos (13) & 11,4 & 43,8 \\
\hline Fabricação de aço e derivados (14) & 0,3 & 78,5 \\
\hline Metalurgia de metais não ferrosos (15) & 0,2 & 17,8 \\
\hline Produtos de metal — exlcusive máquinas e equipaentos (16) & 2,5 & 140,3 \\
\hline Máquinas e equipamentos, inclusive manutenção e reparos (17) & 0,8 & 306,9 \\
\hline Eletrodomésticos (18) & 0,0 & 2,3 \\
\hline Máquinas para escritório e equipamentos de informática (19) & 0,1 & 6,6 \\
\hline Máquinas, aparelhos e materiais elétricos (20) & 1,2 & 46,5 \\
\hline Material eletrônico e equipamentos de comunicações (21) & 0,1 & 15,4 \\
\hline Aparelhos/instrumentos médico-hospitalar, medida e óptico (22) & 0,1 & 17,8 \\
\hline Indústria automobilística (23) & 1,2 & 307,5 \\
\hline Outros equipamentos de transporte (24) & 0,1 & 16,0 \\
\hline Móveis e produtos das indústrias diversas (25) & 23,2 & 134,7 \\
\hline Produção e distribuição de eletricidade e gás, água, esgoto e limpeza urbana (26) & 101,6 & 68,5 \\
\hline Construção civil (27) & 1,4 & 285,1 \\
\hline Comércio e serviços de manutenção e reparação (28) & 22,1 & 761,6 \\
\hline Serviços de alojamento e alimentação (29) & 33,2 & 90,4 \\
\hline Transporte, armazenagem e correio (30) & 40,6 & 330,9 \\
\hline Serviços de informação (31) & 86,2 & 111,8 \\
\hline Intermediação financeira, seguros e previdência complementar e serviços (32) & 22,0 & 291,8 \\
\hline Serviços prestados as empresas (33) & 15,8 & 199,0 \\
\hline Atividades imobiliárias e aluguéis (34) & 8,1 & 260,8 \\
\hline Administração, saúde e educação públicas e seguridade social (35) & 2,4 & 716,5 \\
\hline Serviços prestados às famílias e associativa (36) & 1,4 & 172,5 \\
\hline Outros serviços (37) & 0,1 & 263,8 \\
\hline Total & 965,1 & 6996,4 \\
\hline
\end{tabular}




\section{Tabela 2: Queda do Valor Adicionado Bruto Gaúcho decorrente do aumento de $5 \%$ do ICMS para setores selecionados.}

(Milhões R\$)

\begin{tabular}{|c|c|c|}
\hline \multirow{2}{*}{ Atividades } & \multicolumn{2}{|c|}{ Queda no valor adicionado bruto } \\
\hline & Cenário 1 & Cenário 2 \\
\hline Agricultura, silvicultura e exploração florestal (1) & 49,6 & 193,4 \\
\hline Pecuária e pesca $(2)$ & 24,1 & 95,2 \\
\hline Indústria extrativa (3) & 4,0 & 2,7 \\
\hline Alimentos e bebidas (4) & 14,1 & 71,7 \\
\hline Produtos do fumo (5) & 1,7 & 10,0 \\
\hline Têxteis, artefatos do vestuário e do couro, acessórios e calçados (6) & 14,1 & 80,9 \\
\hline Produtos de madeira - exclusive móveis (7) & 2,8 & 13,1 \\
\hline Celulose e produtos de papel (8) & 2,9 & 8,7 \\
\hline Jornais, revistas, discos (9) & 2,7 & 21,4 \\
\hline Refino de petróleo e gás e produtos químicos (10) & 16,9 & 46,5 \\
\hline 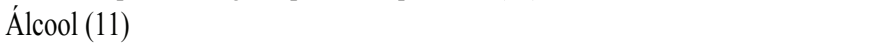 & 0,0 & 0,0 \\
\hline Artigos de borracha e plástico (12) & 1,5 & 24,0 \\
\hline Produtos de minerais não metálicos (13) & 4,2 & 16,1 \\
\hline Fabricação de aço e derivados (14) & 0,1 & 19,4 \\
\hline Metalurgia de metais não ferrosos (15) & 0,1 & 6,2 \\
\hline Produtos de metal — exlcusive máquinas e equipaentos (16) & 1,0 & 57,5 \\
\hline Máquinas e equipamentos, inclusive manutenção e reparos (17) & 0,2 & 80,7 \\
\hline Eletrodomésticos (18) & 0,0 & 0,6 \\
\hline Máquinas para escritório e equipamentos de informática (19) & 0,0 & 2,7 \\
\hline Máquinas, aparelhos e materiais elétricos (20) & 0,3 & 12,9 \\
\hline Material eletrônico e equipamentos de comunicações (21) & 0,0 & 6,2 \\
\hline Aparelhos/instrumentos médico-hospitalar, medida e óptico (22) & 0,0 & 9,8 \\
\hline Indústria automobilística (23) & 0,3 & 68,4 \\
\hline Outros equipamentos de transporte (24) & 0,0 & 4,5 \\
\hline Móveis e produtos das indústrias diversas (25) & 9,1 & 52,4 \\
\hline Produção e distribuição de eletricidade e gás, água, esgoto e limpeza urbana (26) & 42,3 & 28,5 \\
\hline Construção civil (27) & 0,7 & 150,1 \\
\hline Comércio e serviços de manutenção e reparação (28) & 15,6 & 538,1 \\
\hline Serviços de alojamento e alimentação (29) & 12,0 & 32,7 \\
\hline Transporte, armazenagem e correio (30) & 19,2 & 156,3 \\
\hline Serviços de informação (31) & 43,0 & 55,8 \\
\hline Intermediação financeira, seguros e previdência complementar e serviços (32) & 13,9 & 184,0 \\
\hline Serviços prestados as empresas (33) & 9,0 & 113,3 \\
\hline Atividades imobiliárias e aluguéis (34) & 7,7 & 248,6 \\
\hline Administração, saúde e educação públicas e seguridade social (35) & 1,5 & 463,9 \\
\hline Serviços prestados às famílias e associativa (36) & 0,7 & 87,3 \\
\hline Outros serviços (37) & 0,1 & 166,0 \\
\hline Total & 315,5 & 3129,6 \\
\hline
\end{tabular}


Tabela3: Arrecadação ICMS, Rio Grande do Sul.

\begin{tabular}{cc}
\cline { 2 - 3 } Período & Valor Total \\
\hline 2000 & RS 19.374.684.622,77 \\
2001 & RS 20.861.288.921,90 \\
2002 & RS 20.335.075.982,49 \\
2003 & RS 20.058.637.509,97 \\
2004 & RS 19.631.936.743,90 \\
2005 & RS 21.925.672.042,34 \\
2006 & RS 22.361.061.525,11 \\
2007 & RS 22.065.148.113,76 \\
2008 & RS 24.008.317.396,51 \\
2009 & RS 24.008.871.865,15 \\
2010 & RS 26.954.326.084,12 \\
2011 & RS 27.074.241.745,85 \\
2012 & RS 27.997.461.242,88 \\
2013 & RS 29.705.158.459,67 \\
2014 & RS 30.307.947.706,30 \\
2015 & RS 29.751.911.294,42 \\
2016 & RS 31.040.000.000,00*
\end{tabular}

Fonte: Secretaria da Fazenda do RS.

Nota: Dados deflacionados pelo IGP-DI.

* Valor esperado para a arrecadação estadual com ICMS decorrente do aumento deste imposto.

\subsection{Impacto no Emprego}

Quanto à geração de empregos, os resultados do Cenário 1, apresentados na Tabela 4, registram uma redução de aproximadamente 12,2 mil empregos. Cabe frisar, contudo, que esse montante representa apenas um piso (mínimo) a partir do qual o emprego decrescerá. Isso representa uma queda de $0,19 \%$ do pessoal ocupado da economia gaúcha.

No nível setorial, os maiores geradores de desemprego foram o comércio e a agricultura. Devido aos elevados encadeamentos com os demais setores, houve uma queda substancial do emprego estadual. Assim, espera-se que, no período, o aumento nos impostos cause um impacto negativo no nível de pessoal ocupado.

No que tange aos resultados da destruição de empregos para o Cenário 2, observa-se a queda de 114,4 mil empregos na economia. Essa queda representa $-1,80 \%$ no curto/médio prazo. Nesse contexto, o aumento do desemprego provocará a precarização da situação econômica. Para mais detalhes, ver as cifras da Tabela 4.

Em linhas gerais, pode-se inferir que o aumento do ICMS impactará negativamente a economia gaúcha no curto/médio prazo. O aprofundamento dessa tendência, juntamente com a redução dos gastos públicos, contribuirá para o enfraquecimento da economia regional. Estima-se que os resultados reais do aumento do ICMS encontrem-se no intervalo entre os dois cenários apresentados. 


\section{Tabela 4: Redução do Pessoal Ocupado Gaúcho decorrente do aumento de $5 \%$ do ICMS para setores selecionados.}

(Milhões R\$)

\begin{tabular}{|c|c|c|}
\hline \multirow[b]{2}{*}{ Atividades } & \multicolumn{2}{|c|}{ Número de empregos perdidos } \\
\hline & Cenário 1 & Cenário 2 \\
\hline Agricultura, silvicultura e exploração florestal (1) & 3414,8 & 13324,0 \\
\hline Pecuária e pesca (2) & 1683,4 & 6643,8 \\
\hline Indústria extrativa (3) & 195,3 & 131,0 \\
\hline Alimentos e bebidas (4) & 625,7 & 3188,9 \\
\hline Produtos do fumo (5) & 30,3 & 174,3 \\
\hline Têxteis, artefatos do vestuário e do couro, acessórios e calçados (6) & 1019,0 & 5860,2 \\
\hline Produtos de madeira — exclusive móveis (7) & 130,5 & 621,4 \\
\hline Celulose e produtos de papel (8) & 73,8 & 222,0 \\
\hline Jornais, revistas, discos (9) & 91,9 & 717,7 \\
\hline Refino de petróleo e gás e produtos químicos (10) & 173,3 & 477,7 \\
\hline 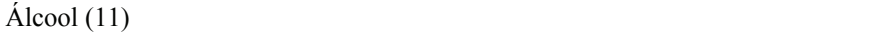 & 0,0 & 0,0 \\
\hline Artigos de borracha e plástico (12) & 43,3 & 692,3 \\
\hline Produtos de minerais não metálicos (13) & 183,5 & 703,5 \\
\hline Fabricação de aço e derivados (14) & 0,7 & 159,5 \\
\hline Metalurgia de metais não ferrosos (15) & 1,9 & 185,8 \\
\hline Produtos de metal — exlcusive máquinas e equipaentos (16) & 29,6 & 1664,0 \\
\hline Máquinas e equipamentos, inclusive manutenção e reparos (17) & 4,5 & 1743,0 \\
\hline Eletrodomésticos (18) & 0,1 & 26,3 \\
\hline Máquinas para escritório e equipamentos de informática (19) & 0,5 & 44,4 \\
\hline Máquinas, aparelhos e materiais elétricos (20) & 8,1 & 322,8 \\
\hline Material eletrônico e equipamentos de comunicações (21) & 0,7 & 98,5 \\
\hline Aparelhos/instrumentos médico-hospitalar, medida e óptico (22) & 0,5 & 150,2 \\
\hline Indústria automobilística (23) & 4,2 & 1107,9 \\
\hline Outros equipamentos de transporte (24) & 1,0 & 108,0 \\
\hline Móveis e produtos das indústrias diversas (25) & 320,8 & 1858,3 \\
\hline Produção e distribuição de eletricidade e gás, água, esgoto e limpeza urbana (26) & 433,4 & 292,1 \\
\hline Construção civil (27) & 38,3 & 7729,4 \\
\hline Comércio e serviços de manutenção e reparação (28) & 705,1 & 24244,1 \\
\hline Serviços de alojamento e alimentação (29) & 1183,1 & 3221,9 \\
\hline Transporte, armazenagem e correio (30) & 550,0 & 4478,3 \\
\hline Serviços de informação (31) & 665,3 & 863,2 \\
\hline Intermediação financeira, seguros e previdência complementar e serviços (32) & 84,0 & 1112,3 \\
\hline Serviços prestados as empresas (33) & 463,9 & 5848,7 \\
\hline Atividades imobiliárias e aluguéis (34) & 27,8 & 899,0 \\
\hline Administração, saúde e educação públicas e seguridade social (35) & 32,0 & 9674,3 \\
\hline Serviços prestados às famílias e associativa (36) & 31,6 & 3842,9 \\
\hline Outros serviços (37) & 3,8 & 12038,5 \\
\hline Total & 12255,6 & 114470,3 \\
\hline
\end{tabular}

FONTE DOS DADOS BRUTOS: MIP-RS, 2008.

\section{Conclusão}

O objetivo deste artigo foi examinar o impacto do aumento do ICMS na estrutura da economia gaúcha em 2008, empregando uma abordagem qualitativa e quantitativa de insumo-produto. Empregou-se o método de coeficientes importantes (CIs) e dos multiplicadores de insumo-produto. 
Os resultados sugerem que o aumento do ICMS terá impactos negativos na economia estadual. No agregado da economia, espera-se que a queda do valor da produção esteja no intervalo entre $0,24 \%$ e $1,75 \%$. Seguindo a queda no valor bruto da produção, o valor adicionado bruto e o pessoal ocupado também apresentarão redução. Segundo nossas estimativas, a queda no pessoal ocupado ficará entre $0,19 \%$ e $1,80 \%$. Estima-se uma queda máxima de 114,4 mil empregos no curto prazo.

Pode-se concluir, portanto, que ambos os cenários indicam uma deterioração da situação econômica do Rio Grande do Sul. O aprofundamento dessas políticas limitará o desenvolvimento da economia gaúcha.

\section{Referências}

AROCHE-REYES, F. (1996). Important coefficient and structural change: a multi-layer approach. Economic Systems Research, v. 8, England. crossref https://doi. org/10.1080/09535319600000017

AROCHE-REYES, F. (2002). Structural transformation and important coefficients in the North American Economies. Economic Systems Research, v. 14, n. 3, England. crossref https://doi.org/10.1080/0953531022000002503

BERNI, D., LAUTERT, V. (2011). Mesoeconomia: Lições de Contabilidade Social. Porto Alegre, Bookman.

BORGES, R.E.S.; MONTIBELER, E.E. Input-Output Matrix Study: A Theoretical Frame to Study the Impact of Brazilian IPI Reduction in Final Demand. Economia, v. 15, p. 228-241.

CAMPBELL, J. (1974). Selected aspects of the interindustry structure of the state of Washington, 1967. Economic Geography, 50. crossref https://doi. org/10.2307/ 143004

CAMPBELL, J. (1975). Application of graph theoretic analysis to interindustry relationships. Regional Science and Urban Economics, v. 5. crossref https://doi. org/10.1016/0166-0462(75)90015-0

CEPAL (Comissão Econômica para América Latina e Caribe) (2012), "CEPALSTAT”, http://www.eclac.org/estadisticas

CRUZ, F. I. L. Riscos nas receitas de ICMS. Carta de Conjuntura FEE, v. 25, n. 2, Porto Alegre. 
DEATON, A. (2003), "Health, Inequality, and Economic Development",Journal of Economic Literature, vol. 41, $\mathrm{N}^{\circ} 1$, Estados Unidos, American Economic Association. crossref https://doi.org/10.1257/jel.41.1.113

DIETZENBACHER, E., 1992. The measurement of interindustry linkages: Key sectors in the Netherlands. Economic Modeling, 9, pp. 419-437. crossref https://doi.org/10.1016/0264-9993(92)90022-T

FOCHEZATTO, A. 2002. Testando um modelo de equilíbrio geral computável para a economia gaúcha: impactos da reestruturação tributária. In: Encontro DE ECONOMIA GAÚCHA, 1, 2002, Porto Alegre. [Anais...] Porto Alegre: PUC-RS.

GOSH, S.; ROY, J. (1998). Qualitative input-output analysis of the Indian economic structure. Economic Systems Research, v. 10, n. 3, England. crossref https://doi.org/10.1080/762947111

GRIJÓ, E.; BERNI, D. (2006). A Metodologia Completa para a Estimativa de Matrizes de Insumo-Produto. Teoria e Evidência Empírica, 14, 9-42.

GUILHOTO, J. J. M., U. A. SESSO (2005). Estimação da Matriz Insumo-Produto a Partir de Dados Preliminares das Contas Nacionais. Economia Aplicada, 9, 1-23.

HARBERGER, A. (1964). Taxation, resource allocation, and welfare. In The role of direct and indirect taxes in the Federal Reserve System (pp. 25-80). Princeton University Press. crossref https://doi.org/10.1515/9781400875931-003

HEWINGS, J. D.; FONSECA, M.; GUILHOTO, J.; SONIS, M. Key sectors and structural change in the Brazilian economy: A comparison of alternative approaches and their policy implications. Journal of Policy Modeling, v. 11, n. 1, p. 67-90, 1989. crossref https://doi.org/10.1016/0161-8938(89)90025-2

IBGE (Instituto Brasileiro de Geografia e Estatística) (2011). "Tabela de Recursos e Usos", http://www.ibge.gov.br/home/estatistica/economia/contasnacionais/2011

ILO (INTERNATIONAL LABOUR ORGANIZATION) (2011), "Studies on Growth with Equity. Brazil: An Innovative Income-led Strategy”, Geneva, International Institute for Labour Studies.

IPEA (Instituto de Pesquisas Econômicas Aplicadas) (2011), "Estatísticas Sociais", http://www.ipeadata.gov.br

LEONTIEF, W. (1986). Input-Output Economics. New York, Oxford University Press. 
MARQUES JUNIOR, L.S.; OLIVEIRA, A.C. (2015). As elasticidades de curto e longo prazos do ICMS no Rio Grande do Sul. Ensaios FEE, v. 36, n. 2, p. 363-382.

MARQUETTI, A. A. (2000), Estimativa do estoque de riqueza tangível no Brasil, 1950-1998, Nova Economia, vol. 10, n. 2, UFMG, Minas Gerais.

MARQUETTI, A. A.; KOSHIAMA, D.; ALENCASTRO, D. (2009), "O aumento da lucratividade expande a acumulação de capital? Uma análise de causalidade de Granger para países da OCDE", Revista de Economia Contemporânea (REC), vol. 13, n. 3, Rio de Janeiro. crossref https://doi.org/10.1590/S141598482009000300001

MILLER, R. E., BLAIR, P. D. (1985). Input-Output Analysis: Foundations and Extensions. Englewood Cliffs, Prentice-Hall.

MILLER, R. E., BLAIR, P. D. (2009). Input-Output Analysis: Foundations and Extensions. Englewood Cliffs, Prentice-Hall. crossref https://doi.org/10.1017/ CBO9780511626982

MONTOYA, M. A. (2012). Fontes de crescimento e mudança estrutural na economia gaúcha: uma análise de valor bruto de produção (VBP) e do emprego. Ensaios FEE, v. 33, n. 2.

NODEXL. http://nodexl.codeplex.com/

PINTOS-PAYERAS (2009). Estimação do sistema quase ideal de demanda para uma cesta ampliada de produtos empregando dados da POF de 2002-2003. Economia Aplicada, v. 13, n. 2, 2009, pp. 231-255. crossref https://doi.org/10.1590/ S1413-80502009000200003

PORSSE, A.A. 2005. Competição tributária regional, externalidades fiscais e federalismo no Brasil: uma abordagem de equilíbrio geral computável. Porto Alegre, RS. Tese de Doutorado. Universidade Federal do Rio Grande do Sul, 146 p.

RASMUSSEN, N.P., 1956. Studies in Intersectoral Relation. North-Holland, Amsterdam.

SCHINTKE, J.; STAGLIN, R. (1988). Important input coefficients in market transaction tables and production flows tables, in M. CIASCHINI (ED.) Input-output analysis, current developments. New York. crossref https://doi.org/10.1007/97894-009-2607-3_3 
SECRETARIA DA FAZENDA DO RIO GRANDE DO SUL (2016). Estatísticas de Arrecadação, disponível em: https://www.sefaz.rs.gov.br/Site/index.aspx?

SOUZA, N. J. (1989). O método dos dígrafos: uma aplicação para matrizes de relações interindustriais do Brasil de 1975. Pesquisa e Planejamento Econômico, v. 19, n. 3, p. 613-41.

THOMAS, V. B. (1982). Input-output Analysis in Developing Countries: Sources, Methods and Applications. John Wiley and Sons Ltd.

UNITED NATIONS (2010), World Economic Situation and Prospects 2010, UN, New York.

Recebido em 07.02.16

Aprovado em 19.08.16 


\section{Apêndice}

Tabela 5: Matriz Adjacente da economia gaúcha, 2008.

\begin{tabular}{|c|c|c|c|c|c|c|c|c|c|c|c|c|c|c|c|c|c|c|c|c|c|c|c|c|c|c|c|c|c|c|c|c|c|c|c|c|c|c|}
\hline tores & & & & & & & & & & & & & & & & & & & & & & & & & & & & & & & & & & & & & & \\
\hline 01 & 1 & & 0 & 1 & & 0 & 0 & 0 & 0 & 0 & 0 & 0 & 0 & 0 & 0 & 0 & 0 & 0 & 0 & 0 & 0 & 0 & 0 & 0 & 0 & 0 & 0 & 0 & ) & 0 & 0 & 0 & 0 & 0 & 0 & 0 & 0 & \\
\hline 02 & 0 & & 0 & 1 & 0 & 0 & 0 & 0 & 0 & 0 & 0 & 0 & 0 & 0 & 0 & 0 & 0 & 0 & 0 & 0 & 0 & 0 & 0 & 0 & 0 & 0 & 0 & 0 & & 0 & 0 & 0 & 0 & 0 & 0 & 0 & 0 & \\
\hline 03 & 0 & 0 & 0 & 0 & 0 & 0 & 0 & 0 & 0 & 1 & 0 & 0 & 0 & 1 & 0 & 0 & 0 & 0 & 0 & 0 & 0 & 0 & 0 & 0 & 0 & 0 & 0 & 0 & & 0 & 0 & 0 & 0 & 0 & 0 & 0 & 0 & \\
\hline 04 & 0 & 0 & 0 & 1 & 0 & 0 & 0 & 0 & 0 & 0 & 0 & 0 & 0 & 0 & 0 & 0 & 0 & 0 & 0 & 0 & 0 & 0 & 0 & 0 & 0 & 0 & 0 & 0 & & 0 & 0 & 0 & 0 & 0 & 0 & 0 & 0 & \\
\hline 05 & 0 & 0 & 0 & 0 & 0 & 0 & 0 & 0 & 0 & 0 & 0 & 0 & 0 & 0 & 0 & 0 & 0 & 0 & 0 & 0 & 0 & 0 & 0 & 0 & 0 & 0 & 0 & 0 & & 0 & 0 & 0 & 0 & 0 & 0 & 0 & 0 & \\
\hline 06 & 0 & 0 & 0 & 0 & 0 & 1 & 0 & 0 & 0 & 0 & 0 & 0 & 0 & 0 & 0 & 0 & 0 & 0 & 0 & 0 & 0 & 0 & 0 & 0 & 0 & 0 & 0 & 0 & & 0 & 0 & 0 & 0 & 0 & 0 & 0 & 0 & \\
\hline 07 & 0 & 0 & 0 & 0 & 0 & 0 & 1 & 0 & 0 & 0 & 0 & 0 & 0 & 0 & 0 & 0 & 0 & 0 & 0 & 0 & 0 & 0 & 0 & 0 & 1 & 0 & 0 & 0 & & 0 & 0 & 0 & 0 & 0 & 0 & 0 & 0 & \\
\hline 08 & 0 & 0 & 0 & 0 & 0 & 0 & 0 & 1 & 0 & 0 & 0 & 0 & 0 & 0 & 0 & 0 & 0 & 0 & 0 & 0 & 0 & 0 & 0 & 0 & 0 & 0 & 0 & 0 & & 0 & 0 & 0 & 0 & 0 & 0 & 0 & 0 & \\
\hline 09 & 0 & 0 & 0 & 0 & 0 & 0 & 0 & 0 & 0 & 0 & 0 & 0 & 0 & 0 & 0 & 0 & 0 & 0 & 0 & 0 & 0 & 0 & 0 & 0 & 0 & 0 & 0 & 0 & & 0 & 0 & 0 & 0 & 1 & 0 & 0 & 0 & \\
\hline 10 & 1 & 0 & 0 & 0 & 0 & 0 & 0 & 0 & 0 & 1 & 0 & 0 & 0 & 0 & 0 & 0 & 0 & 0 & 0 & 0 & 0 & 0 & 0 & 0 & 0 & 0 & 0 & 0 & & 0 & 0 & 0 & 0 & 0 & 0 & 0 & 0 & \\
\hline 11 & 0 & 0 & 0 & 0 & 0 & 0 & 0 & 0 & 0 & 0 & 0 & 0 & 0 & 0 & 0 & 0 & 0 & 0 & 0 & 0 & 0 & 0 & 0 & 0 & 0 & 0 & 0 & 0 & ) & 0 & 0 & 0 & 0 & 0 & 0 & 0 & 0 & \\
\hline 12 & 0 & 0 & 0 & 0 & 0 & 0 & 0 & 0 & 0 & 0 & 0 & 0 & 0 & 0 & 0 & 0 & 0 & 0 & 0 & 0 & 0 & 0 & 0 & 0 & 0 & 0 & 0 & 0 & & 0 & 0 & 0 & 0 & 0 & 0 & 0 & 0 & \\
\hline 13 & 0 & 0 & 0 & 0 & 0 & 0 & 0 & 0 & 0 & 0 & 0 & 0 & 0 & 0 & 0 & 0 & 0 & 0 & 0 & 0 & 0 & 0 & 0 & 0 & 0 & 0 & 0 & 0 & & 0 & 0 & 0 & 0 & 0 & 0 & 0 & 0 & \\
\hline 14 & 0 & 0 & 0 & 0 & 0 & 0 & 0 & 0 & 0 & 0 & 0 & 0 & 0 & 1 & 0 & 1 & 1 & 1 & 0 & 0 & 0 & 0 & 1 & 0 & 0 & 0 & 0 & 0 & 0 & 0 & 0 & 0 & 0 & 0 & 0 & 0 & 0 & \\
\hline 15 & 0 & 0 & 0 & 0 & 0 & 0 & 0 & 0 & 0 & 0 & 0 & 0 & 0 & 1 & 1 & 1 & 1 & 0 & 0 & 1 & 0 & 1 & 0 & 0 & 0 & 0 & 0 & 0 & & 0 & 0 & 0 & 0 & 0 & 0 & 0 & 0 & \\
\hline 16 & 0 & 0 & 0 & 0 & 0 & 0 & 0 & 0 & 0 & 0 & 0 & 0 & 0 & 1 & 0 & 1 & 1 & 0 & 0 & 1 & 0 & 0 & 0 & 0 & 0 & 0 & 0 & 0 & & 0 & 0 & 0 & 0 & 0 & 0 & 0 & 0 & \\
\hline 17 & 0 & 0 & 0 & 0 & 0 & 0 & 0 & 0 & 0 & 0 & 0 & 0 & 0 & 0 & 0 & 0 & 0 & 0 & 0 & 0 & 0 & 0 & 0 & 0 & 0 & 0 & 0 & 0 & 0 & 0 & 0 & 0 & 0 & 0 & 0 & 0 & 0 & \\
\hline 18 & 0 & 0 & 0 & 0 & 0 & 0 & 0 & 0 & 0 & 0 & 0 & 0 & 0 & 0 & 0 & 0 & 0 & 1 & 0 & 0 & 0 & 0 & 0 & 0 & 0 & 0 & 0 & 0 & 0 & 0 & 0 & 0 & 0 & 0 & 0 & 0 & 0 & 0 \\
\hline 19 & 0 & 0 & 0 & 0 & 0 & 0 & 0 & 0 & 0 & 0 & 0 & 0 & 0 & 0 & 0 & 0 & 0 & 0 & 1 & 0 & 0 & 0 & 0 & 0 & 0 & 0 & 0 & 0 & & 0 & 0 & 0 & 0 & 0 & 0 & 0 & 0 & \\
\hline 20 & 0 & 0 & 0 & 0 & 0 & 0 & 0 & 0 & 0 & 0 & 0 & 0 & 0 & 0 & 0 & 0 & 1 & 1 & 0 & 1 & 1 & 0 & 0 & 0 & 0 & 0 & 0 & 0 & 0 & 0 & 0 & 0 & 0 & 0 & 0 & 0 & 0 & \\
\hline 21 & 0 & 0 & 0 & 0 & 0 & 0 & 0 & 0 & 0 & 0 & 0 & 0 & 0 & 0 & 0 & 0 & 0 & 0 & 1 & 0 & 1 & 0 & 0 & 0 & 0 & 0 & 0 & 0 & 0 & 0 & 0 & 0 & 0 & 0 & 0 & 0 & 0 & 0 \\
\hline 22 & 0 & 0 & 0 & 0 & 0 & 0 & 0 & 0 & 0 & 0 & 0 & 0 & 0 & 0 & 0 & 0 & 1 & 1 & 0 & 0 & 0 & 1 & 0 & 0 & 0 & 0 & 0 & 0 & D & 0 & 0 & 0 & 0 & 0 & 0 & 0 & 0 & \\
\hline 23 & 0 & 0 & 0 & 0 & 0 & 0 & 0 & 0 & 0 & 0 & 0 & 0 & 0 & 0 & 0 & 0 & 0 & 0 & 0 & 0 & 0 & 0 & 1 & 0 & 0 & 0 & 0 & 0 & 0 & 0 & 0 & 0 & 0 & 0 & 0 & 0 & 0 & \\
\hline 24 & 0 & 0 & 0 & 0 & 0 & 0 & 0 & 0 & 0 & 0 & 0 & 0 & 0 & 0 & 0 & 0 & 0 & 0 & 0 & 0 & 0 & 0 & 0 & 1 & 0 & 0 & 0 & 0 & 0 & 0 & 0 & 0 & 0 & 0 & 0 & 0 & 0 & 0 \\
\hline 25 & 0 & 0 & 0 & 0 & 0 & 0 & 0 & 0 & 0 & 0 & 0 & 0 & 0 & 0 & 0 & 0 & 0 & 0 & 0 & 0 & 0 & 0 & 0 & 0 & 0 & 0 & 0 & 0 & D & 0 & 0 & 0 & 0 & 0 & 0 & 0 & 0 & \\
\hline 26 & 0 & 0 & 0 & 0 & 0 & 0 & 0 & 0 & 0 & 0 & 0 & 0 & 0 & 0 & 0 & 0 & 0 & 0 & 0 & 0 & 0 & 0 & 0 & 0 & 0 & 1 & 0 & 0 & & 0 & 0 & 0 & 0 & 0 & 0 & 0 & 0 & \\
\hline 27 & 0 & 0 & 0 & 0 & 0 & 0 & 0 & 0 & 0 & 0 & 0 & 0 & 0 & 0 & 0 & 0 & 0 & 0 & 0 & 0 & 0 & 0 & 0 & 0 & 0 & 0 & 0 & 0 & 0 & 0 & 0 & 0 & 0 & 0 & 0 & 0 & 0 & 0 \\
\hline 28 & 0 & 0 & 0 & 0 & 0 & 0 & 0 & 0 & 0 & 0 & 0 & 0 & 0 & 0 & 0 & 0 & 0 & 0 & 0 & 0 & 0 & 0 & 0 & 0 & 0 & 0 & 0 & 0 & & 0 & 0 & 0 & 0 & 0 & 0 & 0 & 0 & \\
\hline 29 & 0 & 0 & 0 & 0 & 0 & 0 & 0 & 0 & 0 & 0 & 0 & 0 & 0 & 0 & 0 & 0 & 0 & 0 & 0 & 0 & 0 & 0 & 0 & 0 & 0 & 0 & 0 & 0 & 0 & 0 & 0 & 0 & 0 & 0 & 0 & 0 & 0 & \\
\hline 30 & 0 & 0 & 1 & 0 & 0 & 0 & 0 & 0 & 0 & 0 & 0 & 0 & 0 & 0 & 0 & 0 & 0 & 0 & 0 & 0 & 0 & 0 & 0 & 0 & 0 & 0 & 0 & 0 & 0 & 0 & 0 & 0 & 0 & 0 & 0 & 0 & 0 & 0 \\
\hline 31 & 0 & 0 & 0 & 0 & 0 & 0 & 0 & 0 & 0 & 0 & 0 & 0 & 0 & 0 & 0 & 0 & 0 & 0 & 0 & 0 & 0 & 0 & 0 & 0 & 0 & 0 & 0 & 0 & 0 & 0 & 0 & 1 & 1 & 1 & 0 & 0 & 0 & \\
\hline 32 & 0 & 0 & 0 & 0 & 0 & 0 & 0 & 0 & 0 & 0 & 0 & 0 & 0 & 1 & 0 & 0 & 1 & 0 & 0 & 0 & 0 & 0 & 0 & 0 & 0 & 0 & 0 & 0 & 0 & 0 & 0 & 0 & 1 & 0 & 0 & 1 & 0 & 0 \\
\hline 33 & 0 & 0 & 0 & 0 & 0 & 0 & 0 & 0 & 0 & 0 & 0 & 0 & 0 & 0 & 0 & 0 & 0 & 0 & 0 & 0 & 0 & 0 & 0 & 0 & 0 & 0 & 0 & 0 & 0 & 0 & 0 & 1 & 1 & 0 & 0 & 0 & 0 & 1 \\
\hline 34 & 0 & 0 & 0 & 0 & 0 & 0 & 0 & 0 & 0 & 0 & 0 & 0 & 0 & 0 & 0 & 0 & 0 & 0 & 0 & 0 & 0 & 0 & 0 & 0 & 0 & 0 & 0 & 0 & 0 & 0 & 0 & 0 & 0 & 0 & 0 & 0 & 0 & 0 \\
\hline 35 & 0 & 0 & 0 & 0 & 0 & 0 & 0 & 0 & 0 & 0 & 0 & 0 & 0 & 0 & 0 & 0 & 0 & 0 & 0 & 0 & 0 & 0 & 0 & 0 & 0 & 0 & 0 & 0 & 0 & 0 & 0 & 0 & 0 & 0 & 0 & 0 & 0 & 0 \\
\hline 36 & 0 & 0 & 0 & 0 & 0 & 0 & 0 & 0 & 0 & 0 & 0 & 0 & 0 & 0 & 0 & 0 & 0 & 0 & 0 & 0 & 0 & 0 & 0 & 0 & 0 & 0 & 0 & 0 & 0 & 0 & 0 & 0 & 0 & 0 & 0 & 0 & 0 & 0 \\
\hline 37 & 0 & 0 & 0 & 0 & 0 & 0 & 0 & 0 & 0 & 0 & 0 & 0 & 0 & 0 & 0 & 0 & 0 & 0 & 0 & 0 & 0 & 0 & 0 & 0 & 0 & 0 & 0 & 0 & 0 & 0 & 0 & 0 & 0 & 0 & 0 & 0 & 0 & \\
\hline
\end{tabular}

Fonte: elaboração própria. 